\title{
Erythropoietin May Improve Anemia in Patients with Autoimmune Hemolytic Anemia Associated with Reticulocytopenia
}

\author{
Olga Arbach ${ }^{\mathrm{a}}$ Robert Funck ${ }^{\mathrm{b}}$ Frank Seibt ${ }^{\mathrm{c}} \quad$ Abdulgabar Salama $^{\mathrm{a}}$ \\ ${ }^{a}$ Institute for Transfusion Medicine, Universitätsmedizin Charité - Universitätsmedizin Berlin, \\ ${ }^{b}$ St. Marien Amberg Clinic, Amberg, \\ ${ }^{c}$ Private Internal Medicine Practice, Berlin, Germany
}

\section{Keywords}

Autoimmune hemolytic anaemia - AlHA .

Reticulocytopenia - Anemia · Erythropoietin

\section{Summary}

Background: Management of patients with autoimmune hemolytic anemia (AIHA) and reticulocytopenia remains challenging. Case Reports: Two patients with decompensated AIHA who were receiving immunosuppressive drugs were treated with erythropoietin (EPO). Administration of EPO increased reticulocyte counts and hemoglobin concentrations in both cases. One patient completely recovered following a short course of treatment. Hemolysis could be compensated in the second patient using only mild doses of immunosuppressive drugs in combination with EPO. Conclusion: The administration of EPO should be considered in patients with therapyrefractory AlHA, particularly in the presence of reticulocytopenia.

\section{Introduction}

In patients with active autoimmune hemolytic anemia (AIHA), reticulocytes are often increased. However, reticulocytopenia may occur in only a number of cases and may result in a life-threatening situation with a lack of compensatory mechanisms [1,2].

Interestingly, the reticulocytopenia observed in affected patients may be associated with hyperplasia [3-7] or hypoplasia of bone marrow [8-12]. These findings might be explained by the presence of autoantibodies reacting with red blood cells (RBCs), reticulocytes and/or erythroid progenitor cells

\author{
Schlüsselwörter \\ Autoimmunhämolytische Anämie · AlHA . \\ Retikulozytopenie · Anämie · Erythropoetin
}

\section{Zusammenfassung}

Hintergrund: Das Management von Patienten mit Autoimmunhämolytischer Anämie und begleitender Retikulozytopenie stellt nach wie vor eine Herausforderung dar. Fallberichte: Zwei Patienten mit dekompensierter Autoimmunhämolytischer Anämie, die mit Immunsuppressiva behandelt wurden, erhielten additiv Erythropoetin (EPO). Die Gabe von EPO erhöhte die Retikulozytenzahl sowie die Hämoglobinkonzentration in beiden Fällen. Der erste Patient erholte sich nach kurzer Therapiedauer. Die Hämolyse konnte im zweiten Fall durch EPO und geringe Dosen von Immunsuppression kompensiert werden. Schlussfolgerung: Der Einsatz von EPO sollte in Patienten mit therapierefraktären Verläufen der AlHA erwogen werden, vor allem in Fällen mit begleitender Retikulozytopenie.

[8, 13-15]. In addition, parvovirus B19 infection has also been implicated as a cause of transient aplastic crisis in some cases $[16,17]$. Furthermore, there is evidence which suggests that other mechanisms may be responsible for prolonged episodes of reticulocytopenia in AIHA [3]. Whatever the mechanisms may be, as long as these patients do not respond to treatment of the underlying disease, blood transfusions remain necessary [5, 18-20]. The question whether erythropoietin (EPO) may be effective in such cases has not yet been addressed. Here, we describe two patients with decompensated AIHA of warm type in whom administration of EPO evidently improved both anemia and outcome.

\section{KARGER \\ Fax +497614520714 \\ Information@Karger.de}

www.karger.com

\section{(c) 2012 S. Karger GmbH, Freiburg}

$1660-3796 / 12 / 0393-0221 \$ 38.00 / 0$

Accessible online at:

www.karger.com/tmh
Prof. Dr. Abulgabar Salama.

Institut für Transfusionsmedizin

Charité - Universitätsmedizin Berlin

Augustenburger Platz 1, 13353 Berlin, Germany

Tel. +49 30450 553-012, Fax -932

abdulgabar.salama@charite.de 
Fig. 1. Course of treatment of a 23 -year-old man with massive autoimmune hemolytic anemia.

- $=$ Red blood cell units; $\mathrm{Hb}=$ hemoglobin concentrations; RPI = corrected reticulocyte production index; Cyclo $=$ cyclophosphamide; Pred $=$ prednisolone $;$ Epo = erythropoietin; biw $=$ twice weekly.

Fig. 2. A 78-year-old female with chronic autoimmune hemolytic anemia and renal failure. $\mathbf{\square}=$ Red blood cell unit; $\mathrm{Hb}=$ hemoglobin concentration; RPI = corrected reticulocyte production index; IvIg = intravenous immunoglobulin; Dexa = dexamethasone; Erypo = erythropoietin $336 \mu \mathrm{g}$.
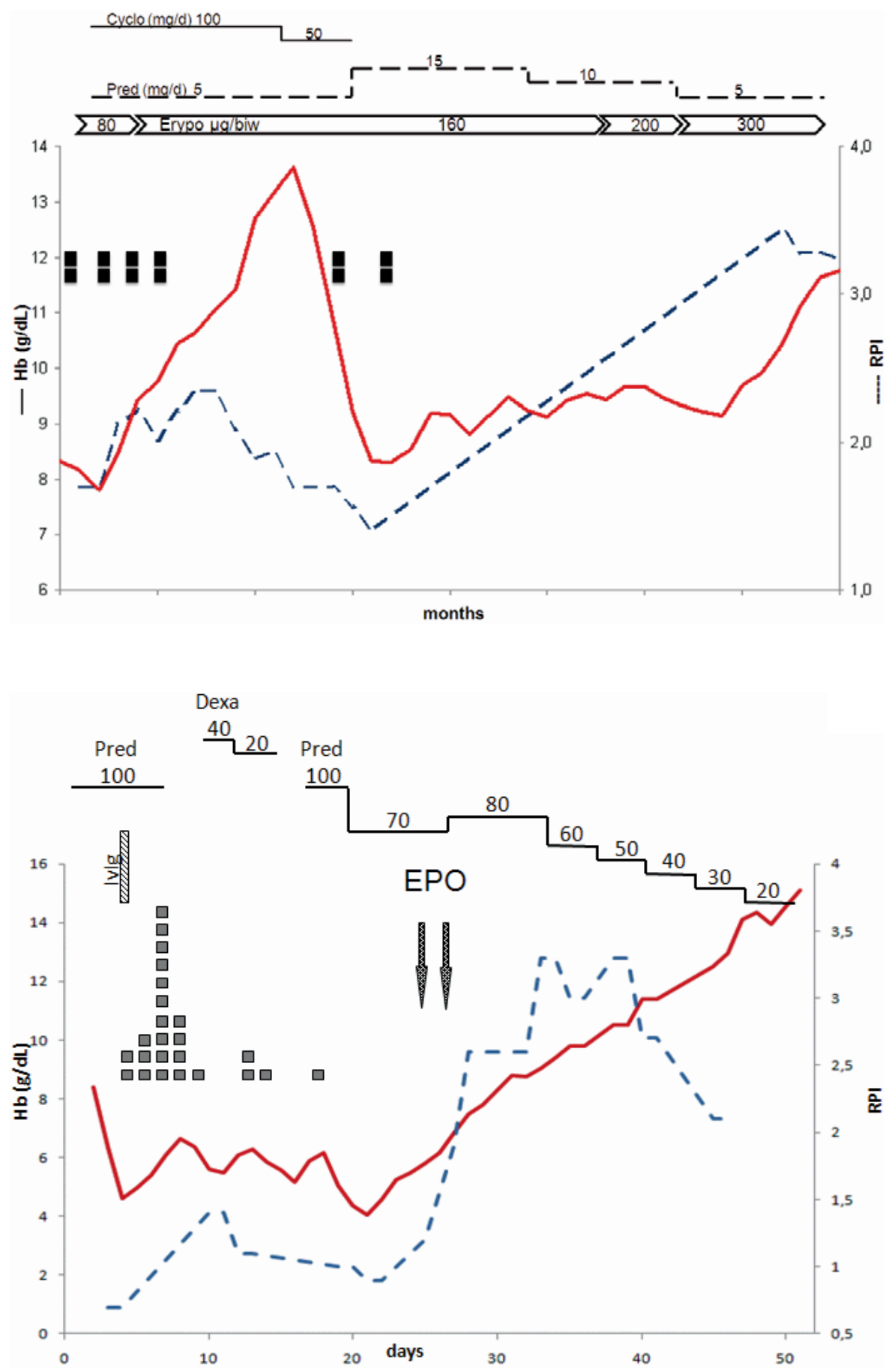

\section{Case Reports}

Case I

A 23-year-old male with massive hemolysis was admitted to the hospital. Laboratory findings revealed the following abnormal values: decreased hemoglobin concentration $(8.4 \mathrm{~g} / \mathrm{dl})$, increased lactate dehydrogenase $(1,300 \mathrm{U} / \mathrm{ml})$, slightly increased reticulocytes $(8.6 \%)$, increased bilirubin $(12 \mathrm{mg} / \mathrm{dl})$, and positive direct and indirect antiglobulin tests, leading to the diagnosis of AIHA of warm type. Despite the administration of $100 \mathrm{mg}$ prednisolone, hemoglobin levels dropped to $4.3 \mathrm{~g} / \mathrm{dl}$ on the second day (fig. 1). A bone marrow biopsy revealed only reactive changes and normal erythropoiesis. Administration of dexamethasone ( $40 \mathrm{mg} /$ day) followed by prednisolone and high-dose intravenous immunoglobulin (IvIg) did not halt hemolysis. Upon observation, anemia could not be corrected by blood transfusion, thus resulting in secondary intensive care. On days 23 and 31, EPO at a concentration of 40,000 IE was administered subcutaneously, and the patients' condition rapidly improved.

\section{Case II}

The second case involved a 78-year-old female with chronic AIHA and accompanying renal failure who was on hemodialysis. Her longstanding AIHA could not be managed without intensive immunosuppressive therapy including azathioprine and cyclophosphamide. Prednisolone dosages were kept at a minimum of $5 \mathrm{mg}$. Immunosuppressive drugs resulted in depressed bone marrow production and leukopoenia together with thrombocytopenia and decompensation of hemoglobin concentration, 
which was observed to repeatedly occur. Continuous treatment with EPO was necessary as this patient also suffered from renal insufficiency. Despite this treatment, hemoglobin concentrations repeatedly deteriorated due to the dual impact of immunosuppression and continuous hemolysis (fig. 2). For over 12 months, the patient required continuous blood transfusions which resulted in an iron overload. As a rescue therapy for hemoglobin recompensation, the dose of EPO was increased from $60 \mu \mathrm{g}$ twice weekly to $300 \mu \mathrm{g}$ twice weekly. Hemoglobin levels were stabilized to normal levels, and the patients' condition improved. During the last 18 months, the patient did not require any further transfusions.

\section{Discussion}

In this case report we described therapy-refractory AIHA associated with relative reticulocytopenia in two patients. The origin of reticulocytopenia in the first patient remained speculative, whereas treatment with cyclophosphamide could at least be partially responsible for the second patients' reticulocytopenia. In both cases, hemolysis could not be halted using standard immunosuppressive drugs. Both patients were seriously compromised and required additional treatment. Due to the relative reticulocytopenia, the use of more aggressive immunosuppressive drugs did not appear to be adequate in both cases. In order to stimulate erythropoiesis, treatment with EPO was initiated in the first patient, and was intensified in the second. Beneficial effects of this treatment were evident in both cases. The first patient recovered from the aplastic crisis, whereas the second patient did not require any further blood transfusions, which was documented for an 18-month period following administration.
EPO has been proven to be an effective form of treatment for anemia related to renal failure, cancer or cancer-related disease, and in rare cases, for anemia related to other causes [21-23]. The mechanism by which EPO may improve the anemia observed in all these conditions is largely or even exclusively reflected by the increased production of RBCs. In contrast, EPO may improve anemia in AIHA via two mechanisms: Firstly, stimulation of RBC production and secondly, decrease in the total amount of autoantibodies present on each RBC, which is secondary to an optimal ratio of an increase in the total number of RBCs to a total constant amount of antibody in the circulation. This is supported by the fact that the destruction of RBCs in AIHA is also related to the autoantibody concentration on RBCs.

Interestingly, the beneficial effect of EPO in AIHA may somewhat resemble that of the thrombopoietin-receptor agonists (TPO) in autoimmune thrombocytopenia. At least $80 \%$ of these patients respond to TPO. Since the mechanisms of both diseases are rather similar, it would not be surprising if most AIHA patients respond to treatment with EPO. If this is indeed the case, the use of less toxic drugs in these patients may now be possible. However, further studies involving larger patient numbers are required in order to allow a final conclusion on the effect and mechanisms of this form of treatment.

\section{Disclosure Statement}

The authors declare no conflict of interest.

\section{References}

$\checkmark 1$ Conley CL, Lippman SM, Ness PM, Petz LD, Branch DR, Gallagher MT: Autoimmune hemolytic anemia with reticulocytopenia and erythroid marrow. N Engl J Med 1982;306:281-286.

2 Conley CL, Lippman SM, Ness P: Autoimmune hemolytic anemia with reticulocytopenia. A medical emergency. JAMA 1980;244:1688-1690.

3 Dacie J: Auto-immune haemolytic anaemia (AIHA): warm antibody syndromes II: 'idiopathic' types: haematological and biochemical findings; in Dacie J (ed): The Haemolytic Anaemias, vol. 3, ed. 3. New York, Churchill Livingstone, 1992, pp 54-93.

4 Liesveld JL, Rowe JM, Lichtman MA: Variability of the erythropoietic response in autoimmune hemolytic anemia: analysis of 109 cases. Blood 1987;69:820-826.

5 Crosby WH, Rappaport H: Reticulocytopenia in autoimmune hemolytic anemia. Blood 1956;11: 929-936.

6 Celada A: Autoimmune haemolytic anaemia and aplastic crisis. Br J Haematol 1984;57:178-190.

7 Harley J, Dods L: Some acquired haemolytic anaemias of childhood. Australas Ann Med 1959;8:98108.

8 Meyer RJ, Hoffman R, Zanjani ED: Autoimmune hemolytic anemia and periodic pure red cell aplasia in systemic lupus erythematosus. Am J Med 1978; 65:342-345.
9 Lees MH, Fisher OD, Shanks JM: Case of immune aplastic haemolytic anaemia with thrombocytopenia. Br Med J 1960;1:110-111.

10 Tomiyama J, Adachi Y, Hanada T, Matsunaga Y: Human parvovirus B19-induced aplastic crisis in autoimmune haemolytic anaemia. Br J Haematol 1988:69:288-289.

11 Lefrere JJ, Courouce AM, Bertrand Y, Girot R, Soulier JP: Human parvovirus and aplastic crisis in chronic hemolytic anemias: a study of 24 observations. Am J Hematol 1986;23:271-275.

12 Bertrand Y, Lefrere JJ, Leverger G, Courouce AM, Feo C, Clark M, Schaison G, Soulier JP: Autoimmune haemolytic anaemia revealed by human parvovirus linked erythroblastopenia. Lancet 1985; ii:382-383.

13 Pisciotta AV, Hinz JE: Occurrence of agglutinogens in normoblasts. Proc Soc Exp Biol Med 1956; 91:356-358.

14 Yunis JJ, Yunis E: Cell antigens and cell specialization. I. A study of blood group antigens on normoblasts. Blood 1963;22:53-65.

15 Mangan KF, Besa EC, Shadduck RK, Tedrow H, Ray PK: Demonstration of two distinct antibodies in autoimmune hemolytic anemia with reticulocytopenia and red cell aplasia. Exp Hematol 1984;12: 788-793.
16 Brown KE: Haematological consequences of parvovirus B19 infection. Baillieres Best Pract Res Clin Haematol 2000;13:245-259.

17 van Elsacker-Niele AM, Kroes AC: Human parvovirus B19: relevance in internal medicine. Neth J Med 1999;54:221-230.

18 Greenberg J, Curtis-Cohen M, Gill FM, Cohen A Prolonged reticulocytopenia in autoimmune hemolytic anemia of childhood. J Pediatr 1980;97:784 786.

19 Olcay L, Duzova A, Gumruk F: A warm antibody mediated acute hemolytic anemia with reticulocytopenia in a four-month-old girl requiring immunosuppressive therapy. Turk J Pediatr 1999;41:239-244.

20 Carapella de Luca E, Stegagno M, Morino G, Ballati G, Lorenzini F: Prolonged reticulocytopenia and transient erythroid hypoplasia in a child with autoimmune haemolytic anaemia. Haematologica 1984;69:315-320.

21 Dicato M, Plawny L: Erythropoietin in cancer patients: pros and cons. Curr Opin Oncol 2010;22: 307-311.

22 Lapchak PA: Carbamylated erythropoietin to treat neuronal injury: new development strategies. Expert Opin Investig Drugs 2008;17:1175-1186.

23 Del Vecchio L, Cavalli A, Tucci B, Locatelli F: Chronic kidney disease-associated anemia: new remedies. Curr Opin Investig Drugs 2010;11:1030-1038. 
Erratum

Transfus Med Hemother 2014;41:341

In the article

Arbach O, Funck R, Seibt F, Salama A: Erythropoietin may improve anemia in patients with autoimmune hemolytic anemia associated with reticulocytopenia. Transfus Med Hemother 2012;39:221-223.

figure 1 and figure 2 were interchanged. Figure 1 represents the data from case no. II and vice versa figure 2 represents the data from case no. I. 